American Journal of Pharmaceutical Education 2017; 81 (1) Article 18.

\title{
COMMENTARY
}

\section{Describing Entrustable Professional Activities Is Merely the First Step}

\author{
Stuart T. Haines, PharmD, ${ }^{\mathrm{a}}$ Amy Pittenger, PhD, PharmD, MS, ${ }^{\mathrm{b}}$ Cecilia Plaza, PhD, PharmD ${ }^{\mathrm{c}}$ \\ ${ }^{a}$ University of Mississippi School of Pharmacy, Jackson, Mississippi \\ ${ }^{\mathrm{b}}$ University of Minnesota College of Pharmacy, Minneapolis, Minnesota \\ ${ }^{c}$ American Association of Colleges of Pharmacy, Alexandria, Virginia \\ Submitted December 20, 2016; accepted January 2, 2017; published February 25, 2017.
}

The profession of pharmacy needs a core set of entrustable professional activities (EPAs) - not only to describe what pharmacists do but also to set expectations and guide future action. Entrustable professional activities are units of work. ${ }^{1}$ They can be observed and assigned by preceptors and supervisors. Unlike competency statements, which can seem abstract and academic to noneducators, ${ }^{2}$ EPAs are intuitively understood by patients, practitioners, and policymakers. The EPAs for New Pharmacy Graduates reported in this issue of the Journal are an important first step, but far more needs to be done. ${ }^{3}$

Entrustable professional activities were first described and subsequently used by medical residency training programs as a means to translate competency statements (ie, general qualities that every health professional should possess) into concrete tasks that supervisors can observe and delegate to trainees in the clinical environment. ${ }^{1}$ Discipline-specific EPAs have been formulated for postgraduate training in family medicine, internal medicine, and pediatrics. ${ }^{4-6}$ In 2014, the Association of American Medical Colleges (AAMC) published a list of 13 core EPAs for entering residency that medical school graduates are expected to perform without direct supervision on day 1 of residency, regardless of specialty. ${ }^{7}$ The enthusiasm and speed with which EPAs have been embraced by medical schools and residency training programs suggests there has been a need for greater clarity regarding a core set of skills that all physicians should possess. Currently, 10 medical schools are pilot testing the AAMC core EPAs. ${ }^{8}$ These institutions will formally report outcomes as well as lessons learned from implementing the EPA framework in their curricula.

The development of the Core EPAs for New Pharmacy Graduates was rigorous. ${ }^{9}$ Although input from a wide range of stakeholders was sought and received, undoubtedly some will view them with skepticism. To

Corresponding Author: Stuart T. Haines, Department of Pharmacy Practice, University of Mississippi School of Pharmacy, 2500 North State St., Jackson, MS 39216. Tel: 601815-1845. E-mail: sthaines@umc.edu some, the EPAs represent yet another mandate that colleges and schools must somehow assimilate into their curricula and use to assess student progress. For others, the EPAs do not reflect their specialized areas of practice. And still others will have difficulty seeing the connection between the EPAs and the content they teach. These are legitimate concerns but miss the point. We argue that a lack of clarity regarding the role and responsibilities of pharmacists has hampered the advancement of pharmacy practice. Today the profession has a shared vision and model of practice. ${ }^{10}$ The accreditation of doctor of pharmacy programs is contingent on producing "practiceready" and "team-ready" graduates. ${ }^{11}$ The Core EPAs for New Pharmacy Graduates reflect these realities.

While the EPAs often are presented as a list of discrete tasks and activities, they are interrelated and overlapping (Figure 1). Moreover, EPAs do not negate the need for a set of underlying competencies. ${ }^{12}$ These competencies, which were derived from the cognitive, affective, and psychomotor domains, are articulated in the CAPE 2013 Educational Outcomes statements. ${ }^{13}$ The EPA statements flow from and are extensions of these competencies (Figure 2). Moreover, the Core EPAs for New Pharmacy Graduates describe the foundation for the development of EPAs for postgraduate pharmacy training programs.

New pharmacy graduates should be able to perform all Core EPAs without direct supervision. ${ }^{9}$ This does not imply that new pharmacy graduates are "fully formed" and no longer will need feedback, guidance, or coaching from exemplary role models after graduation (Table 1). Postgraduate training, both formal and informal, in the workplace after licensure should be structured in a way that will enable new graduates to refine their skills, build their confidence, and increase their proficiency. ${ }^{14}$ Over time, pharmacy graduates should be entrusted to assume greater autonomy and the responsibility of supervising others.

Not surprisingly, several of the Core EPAs for New Pharmacy Graduates mirror AAMC's EPA statements for 


\section{American Journal of Pharmaceutical Education 2017; 81 (1) Article 18.}

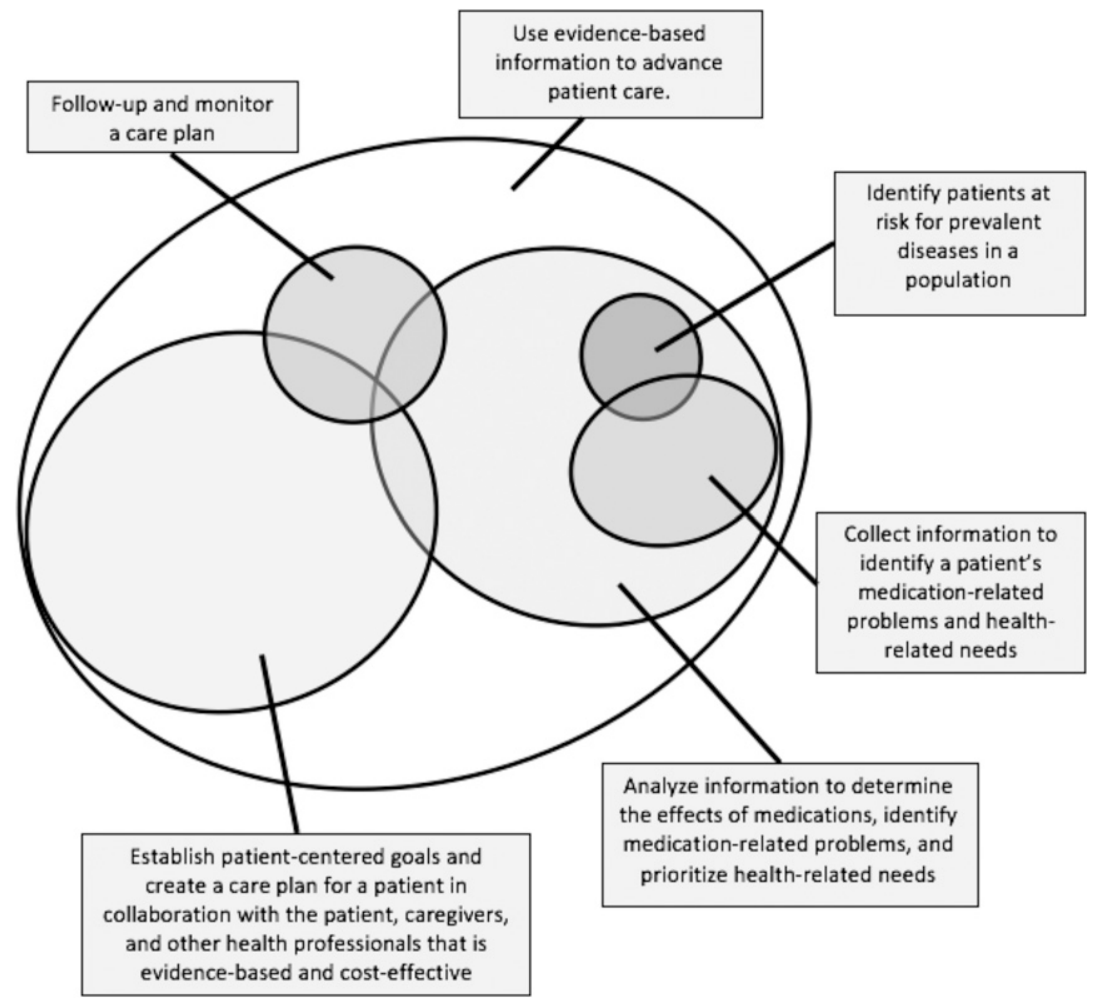

Figure 1. Interdependence of Entrustable Professional Activities

medical school graduates. ${ }^{7}$ For example, collaborating as members of interprofessional teams and using evidencebased information to advance patient-care are essential professional activities for medical and pharmacy graduates. However, the Core EPAs for New Pharmacy Graduates reflect the unique role and responsibilities of pharmacists and take into account that they are fully licensed shortly after graduation. In this regard, pharmacy has an opportunity to use the EPA statements to shape the workplace and clarify roles and responsibilities within a team-based practice model. ${ }^{15}$ Thus, the EPAs may stimulate systemic change, both internal (within pharmacy) and external.

Beyond their use by educational programs, the Core EPAs for New Pharmacy Graduates have potential applications for workforce development and practice evaluation. For instance, EPA statements, coupled with practice-specific tasks, could be used by employers to onboard new employees. They could be used to create workplace EPAs and a corresponding "curriculum" to create concrete and measurable performance objectives for development programs as well as performance indicators for career advancement. In the same way the Core EPAs for New Graduates makes operational competencybased education through measurable units of practice, workplace EPAs could make operational competencybased practice. ${ }^{16}$ Moreover, the processes and framework for entrustment used with trainees can be applied to employees in the workplace. The concept of entrustment for units of practice can only be demonstrated and achieved over time. ${ }^{17}$ Bridging the application of EPAs from school

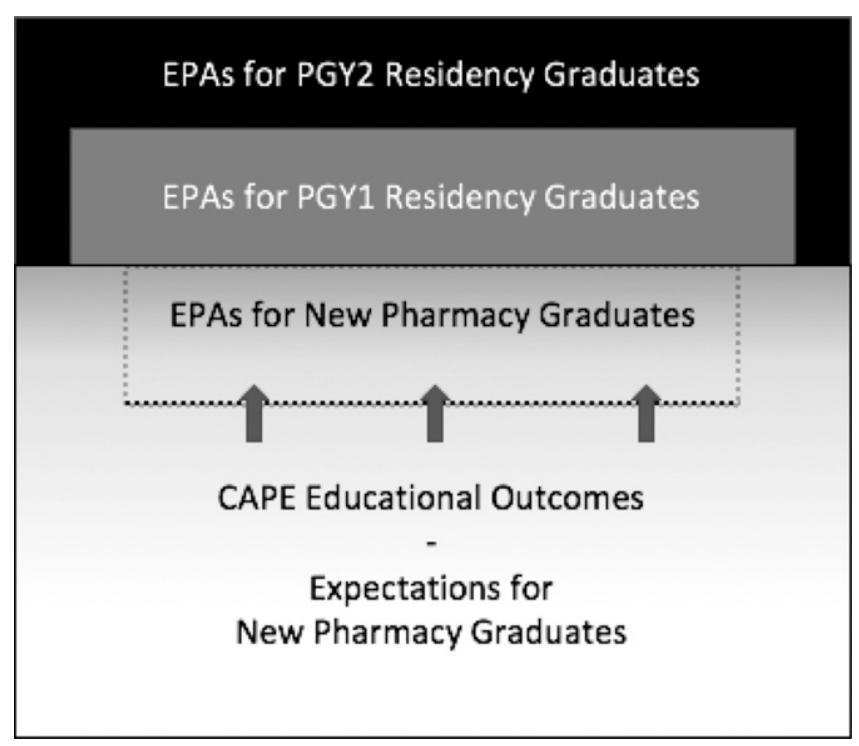

Figure 2. Relationships Between Center for the Advancement of Pharmacy Education (CAPE) - Educational Outcomes, Core Entrustable Professional Activities (EPAs) for New Pharmacy Graduates, and Postgraduate Pharmacy Residency EPAs 
American Journal of Pharmaceutical Education 2017; 81 (1) Article 18.

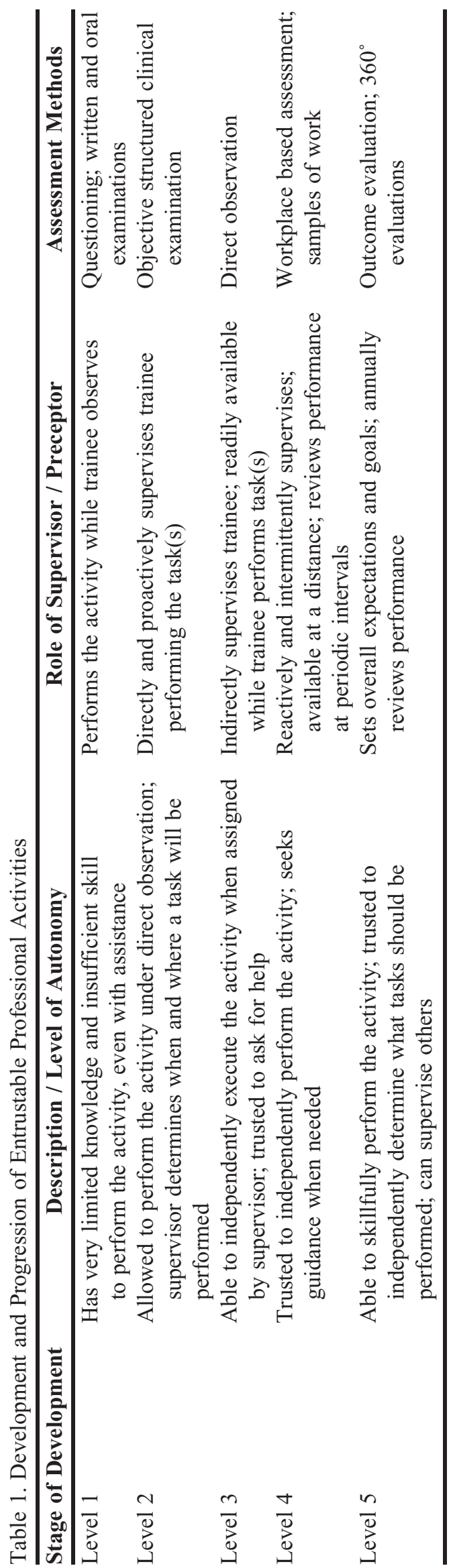

into practice would help standardize the approach and potentially strengthen the alignment between educational programs, residency training, and practice by using similar language and evaluation processes.

In addition, using EPAs in health professions education and in the workplace has the potential to address one of the areas of confusion and conflict encountered within team-based practice models - roles and responsibilities. Interprofessional collaboration is important for pharmacy practice. Without collaboration, especially with medicine colleagues, the pharmacist's scope of practice is limited and relegated to a consultative role, ie, input that is nice to have but not essential. Entrustable professional activities in the workplace specific to interprofessional collaboration can help codify the essential aspects of the pharmacist's role and establish the necessary involvement of pharmacists in primary care settings. ${ }^{18}$

Entrustable professional activities specific to interprofessional, team-based care have been difficult to formulate. Olle ten Cate argues that aspects of interprofessional collaboration (eg,values and ethics, professionalism, teamwork attitudes) are essential components of entrustment but are not units of practice that can be measured through direct observation. ${ }^{16}$ Nonetheless, aspects of interprofessional collaboration (eg, communication practices and handoffs during transitions of care $^{19}$ ) are included in the Core EPAs for New Pharmacy Graduates. There is a major project under way to create EPAs for interprofessional education (IPE) led by recognized IPE scholars Susan Wagner and Scott Reeves. $^{20}$

The 2016-2017 Academic Affairs committee has been charged with developing a roadmap for the implementation of the Core EPAs for New Graduates by colleges and schools of pharmacy as well as conceptualizing additional applications for the EPAs. This includes using EPAs to communicate to prospective students, to inform continuous professional development, and to advocate for health care payment reform. Moreover, EPA statements will be mapped to both the CAPE 2013 Educational Outcomes and the Pharmacist Patient Care Process. ${ }^{10,13}$ The EPA map and the committee recommendations will be presented at the 2017 AACP annual meeting in Nashville, Tennessee.

The pharmacy profession has made a significant investment redefining and articulating what pharmacists do. The Core EPAs for New Pharmacy Graduates furthers this work by creating a common language to guide pharmacy education and professional development. But describing the EPAs is merely the first step. We have much work ahead. 


\section{American Journal of Pharmaceutical Education 2017; 81 (1) Article 18.}

\section{REFERENCES}

1. ten Cate O. Entrustability of professional activities and competency-based training. Med Educ. 2005;39(12):1176-1177. 2. ten Cate O. Competency-based education, entrustable professional activities, and the power of language. J Grad Med Educ. 2013;5(1):6-7. 3. Haines ST, Pittenger AL, Stolte SK, et al. Core entrustable professional activities for new pharmacy graduates. Am J Pharm Educ. 2017;81(1):Article S2.

4. Hauer KE, Kohlwes J, Cornett P, et al. Identifying entrustable professional activities in internal medicine training. J Grad Med Educ. 2013;5(1):54-59.

5. Shaughnessy AF, Sparks J, Cohen-Osher M, Goodell KH, Sawin GL, Gravel J Jr. Entrustable professional activities in family medicine. J Grad Med Educ. 2013;5(1):112-118.

6. The American Board of Pediatrics. Entrustable professional activities. https://www.abp.org/entrustable-professional-activitiesepas. Accessed December 19, 2016.

7. Association of American Medical Colleges. Core entrustable professional activities for entering residency. Curriculum Developers' Guide. 2014. https://members.aamc.org/eweb/upload/ core $\% 20$ EPA\%20Curriculum\%20Dev\%20Guide.pdf. Accessed December 19, 2016.

8. Association of American Medical Colleges. The core entrustable professional activities for entering residency. https:/www.aamc.org/ initiatives/coreepas/. Accessed December 19, 2016.

9. Haines ST, Gleason BL, Kantorovich A, et al. Report of the 20152016 Academic Affairs Standing Committee. Am J Pharm Educ. 2016;80(9):Article S20.

10. Joint Commission of Pharmacy Practitioners. Pharmacists' patient care process. May 29, 2014. https://www.pharmacist.com/sites/default/ files/files/PatientCareProcess.pdf. Accessed December 19, 2016. 11. Accreditation Council for Pharmacy Education. Accreditation standards and key elements for the professional program in pharmacy leading to the doctor of pharmacy degree. https://www.acpe-accredit. org/pdf/Standards2016FINAL.pdf. Accessed December 19, 2016. 12. ten Cate O, Scheele F. Competency-based postgraduate training: can we bridge the gap between theory and clinical practice? Acad Med. 2007;82(6):542-547.

13. Medina MS, Plaza CM, Stowe CD, et al. Center for Advancement of Pharmacy Education 2013 Educational Outcomes. Am J Pharm Educ. 2013;77(8):Article 162.

14. Haines ST. Making residency training an expectation for pharmacists in direct patient care roles. Am J Pharm Educ. 2007;71 (4):Article 71.

15. Mitchell P, Wynia M, Golden R, et al. Core principles \& values of effective team-based health care. Discussion paper. Washington, DC: Institute of Medicine; 2012.

16. ten Cate O, Chen HC, Hoff RG, Peters H, Bok H, van der Schaaf M. Curriculum development for the workplace using entrustable professional activities (EPAs): AMEE Guide No. 99. Med Teach. 2015;37(11):983-1002.

17. Mulder H, ten Cate O, Daalder R, Berkvens J. Building a competency-based workplace curriculum around entrustable professional activities: the case of physician assistant training. Med Teach. 2010;32(10):e453-e459.

18. McBane SE, Dopp AL, Abe A, et al. Collaborative drug therapy management and comprehensive medication management - 2015 . ACCP White Paper. Pharmacother. 2015;35(4):e39-e50. 19. Aylward M, Nixon J, Gladding S. An entrustable professional activity (EPA) for handoffs as a model for EPA assessment development. Acad Med. 2014;89(10):1335-1340.

20. Wagner SJ, Reeves S. Milestones and entrustable professional activities: the key to practically translating competencies for interprofessional education? J Interprof Care 2015;29(5):507-508. 